Article

\title{
Comparative Study on the Antivirus Activity of Shuang-Huang-Lian Injectable Powder and Its Bioactive Compound Mixture against Human Adenovirus III In Vitro
}

\author{
Qinhai Ma ${ }^{1,2,+}$, Dedong Liang ${ }^{1,2,+}$, Shuai Song ${ }^{1,2,+}$, Qintian $\mathrm{Yu}^{1,2}$, Chunyu Shi ${ }^{1,2}$, \\ Xuefeng Xing ${ }^{1,2, *}$ and Jia-Bo Luo ${ }^{1,2, *}$ \\ 1 School of Traditional Chinese Medical Science, Southern Medical University, Guangzhou 510515, China; \\ 13268268214@163.com (Q.M.); famouscool@163.com (D.L.); ss89112@126.com (S.S.); dkdklm@163.com (Q.Y.); \\ 15626452676@163.com (C.S.) \\ 2 Guangdong Provincial Key Laboratory of Chinese Medicine Pharmaceutics, Southern Medical University, \\ Guangzhou 510515, China \\ * Correspondence: xiaoxing0610@163.com (X.X.); ljb@smu.edu.cn (J.-B.L.); \\ Tel./Fax: +86-20-6278-9112 (X.X.); +86-20-6164-8255 (J.-B.L.) \\ + These authors contributed equally to this work.
}

Academic Editor: Curt Hagedorn

Received: 21 January 2017; Accepted: 6 April 2017; Published: 12 April 2017

\begin{abstract}
Shuang-Huang-Lian injectable powder (SHL)—a classical purified herbal preparation extracted from Scutellaria baicalensis, Lonicera japonica, and Forsythia suspense-has been used against human adenovirus III $\left(\mathrm{HAdV}_{3}\right)$ for many years. The combination herb and its major bioactive compounds, including chlorogenic acid, baicalin, and forsythia glycosides A, are effective inhibitors of the virus. However, no comprehensive studies are available on the antiviral effects of SHL against $\mathrm{HAdV}_{3}$. Moreover, it remains unclear whether the mixture of chlorogenic acid, baicalin, and forsythia glycosides A (CBF) has enhanced antiviral activity compared with SHL. Therefore, a comparative study was performed to investigate the combination which is promising for further antiviral drug development. To evaluate their antivirus activity in parallel, the combination ratio and dose of CBF were controlled and consistent with SHL. First, the fingerprint and the ratio of CBF in SHL were determined by high performance liquid chromatography. Then, a plaque reduction assay, reverse transcription polymerase chain reaction (PCR), real-time polymerase chain reaction (qPCR), and enzyme-linked immunosorbent assay (ELISA) were used to explore its therapeutic effects on viral infection and replication, respectively. The results showed that SHL and CBF inhibited doseand time-dependently $\mathrm{HAdV}_{3}$-induced plaque formation in A549 and HEp-2 cells. SHL was more effective than CBF when supplemented prior to and after viral inoculation. SHL prevented viral attachment, internalization, and replication at high concentration and decreased viral levels within and out of cells at non-toxic concentrations in both cell types. Moreover, the expression of tumor necrosis factor alpha (TNF)- $\alpha$, interleukin (IL)-1B, and IL-6 was lower and the expression of interferon (IFN)- $\gamma$ was higher in both cell types treated with SHL than with CBF. In conclusion, SHL is much more effective and slightly less toxic than CBF.
\end{abstract}

Keywords: human adenovirus III; anti-viral; Shuang-Huang-Lian injectable powder; effect comparison

\section{Introduction}

Human adenovirus (HAdV), a nonenveloped DNA virus, is a common causative pathogen of acute respiratory infection. HAdV infection is more common in childcare and overcrowded conditions, 
and at least one strain was detected in most infected children during the first 5 years after birth. Nowadays, seven species, including many genotypes, have been characterized by genomics and bioinformatics [1,2]. HAdV species B (serotypes 3, 7, 14, and 55), species C (serotypes 1, 2, 5, and 6), and species $\mathrm{E}$ (serotype 4 ) are the most commonly found in patients with respiratory infection. Among these, $\mathrm{HAdV}_{3}$ strains of subspecies $\mathrm{B} 1$ are the major epidemic strains responsible for severe respiratory disease epidemics and outbreaks worldwide [3-10]. Currently, there is no effective treatment or vaccine against $\mathrm{HAdV}_{3}$ infection and new anti-HAdV 3 drugs urgently need to be developed.

Shuang-Huang-Lian injectable powder (SHL), consisting of Scutellaria baicalensis, Lonicera japonica, and Forsythia suspense, is a classical prescription in traditional Chinese medicine (TCM). Its efficacy against many infectious diseases caused by bacteria and viruses in respiratory traction has been demonstrated [11]. In 1992, SHL was approved in China as a new Chinese patent drug for emergency treatment. Chlorogenic acid, baicalin, and forsythia glycosides, the main effective compounds isolated from the herb extract, are representative markers of its quality recorded in the Chinese Pharmacopoeia (2015). Chlorogenic acid is the major ingredient of Lonicera japonica that has been reported to have multi-anti-viral activities against human immunodeficiency virus (HIV), adenovirus, influenza virus (H1N1, H5N1), and EV71 [12-16]. Baicalin, which is derived from the dried root of Scutellaria baicalensis, has been demonstrated to inhibit influenza A (H1N1) infection, Dengue virus, and respiratory syncytial virus infection [17-19]. Forsythoside A, the active ingredient of Forsythia suspense, has been shown to inhibit syncytial virus and coxsackievirus in vitro [20]. In addition, forsythoside A has the potential to prevent infectious bronchitis virus (IBV) infection in vitro [21].

Multidrug combination is an important strategy in modern antivirus therapy because of increasing drug resistance. Contrary to single-component drugs, the benefits of TCM drugs are often due to the synergistic interactions of multiple ingredients. Therefore, we hypothesized that the antivirus ability of SHL may occur though the activity of multiple ingredients with multiple targets. Accordingly, a comparative antivirus study of SHL and its major bioactive ingredients mixture was investigated. Antivirus effects, interference link, and regulation of inflammatory cytokines were explored in both HEp-2 and A549 cell lines.

\section{Materials and Methods}

\subsection{Reagents}

SHL (lot\#: 1409422) was provided by Second Chinese Medicine Factory of Harbin Pharm Group Co., Ltd. (Harbin, China). Forsythoside A (94.1\%, lot\#: 111810-201405), baicalin (93.3\%, lot\#: 110715-201318), and chlorogenic acid (96.2\%, lot\#: 110753-201415) were provided by the National Institutes for Food and Drug Control (Beijing, China). Mouse tumor necrosis factor alpha (TNF- $\alpha$ ), interleukin (IL)-1ß, IL-6, and interferon gamma (IFN- $\gamma$ ) enzyme-linked immunosorbent assay (ELISA) kits were obtained from Huamei (Wuhang, China). Premix Taq ${ }^{\mathrm{TM}}$ (TaKaRa Taq ${ }^{\mathrm{TM}}$ Version 2.0) and SYBR Premix Ex Taq II (Tli RNaseH Plus) were purchased from Takara (Tokyo, Japan). The virus DNA extraction kit was obtained from Guangzhou Institute of Respiratory Disease (Guangzhou developed by Pharmaceutical Technology Co., Ltd., Guangzhou, China). Cell counting kit-8 (CCK-8) was from Dojindo (Dojindo, Japan).

\subsection{Chromatographic Conditions and Test Samples Preparation}

The high performance liquid chromatography (HPLC)-diode array detector (DAD) fingerprint of SHL was performed on an Agilent 1200 series liquid chromatography system (Agilent Technologies, Santa Clara, CA, USA), consisting of a binary pump (Agilent G1312B), an auto-sampler (Agilent G1329B), and a DAD-vis detector (Agilent G1316A). The data were recorded and analyzed using Agilent Chemstation software for the LC-3D system (Rev. B.04.03-SP1). A Cosmosil 5C18-AR-II column $\left(5 \mu \mathrm{m}, 4.6 \times 250 \mathrm{~mm}\right.$; Nacalai Tesque Co. Inc., Tokyo, Japan) was used at $30{ }^{\circ} \mathrm{C}$. The mobile phase was composed of $(\mathrm{A})$ phosphoric acid aqueous solution $(0.2 \%, v / v)$ and $(\mathrm{B})$ methanol using a gradient 
elution of $80-70 \%$ (A) at $0-5 \mathrm{~min} ; 70-55 \%$ (A) at 5-35 $\mathrm{min}$; and $55-30 \%$ (A) at $35-50 \mathrm{~min}$. The sample injection volume was $10 \mu \mathrm{L}$ with a flow rate of $1.0 \mathrm{~mL} / \mathrm{min}$. The detection wavelength was set at $327 \mathrm{~nm}$. Three standard references, which were chlorogenic acid, forsythoside A, and baicalin, were used. The stock solutions of standard references were prepared by dissolving accurately the weighed standards in methanol and storing them in a $10 \mathrm{~mL}$ volumetric flask. Otherwise, $20.0 \mathrm{mg}$ SHL was supplemented with $10 \mathrm{~mL}$ methanol and then extracted under sonication for $20 \mathrm{~min}$. All the test samples were filtered through a $0.45 \mu \mathrm{m}$ membrane filter before chromatographic analysis. The HPLC-DAD fingerprint standard of SHL was recorded and compared to these three standard references. HPLC-DAD revealed that SHL contained $1.3 \%$ chlorogenic acid, $0.8 \%$ forsythoside A, and $21.6 \%$ baicalein (Figure 1). Based on the ratios of the three main components of SHL measured by HPLC-DAD, we prepared a mixture of the three main components. Then, the antiviral effect of the mixed standards was compared with that of SHL. The initial concentration of the mixture was $593.3 \mu \mathrm{g} / \mathrm{mL}$ (the rate of the mixture of chlorogenic acid, forsythoside A, and baicalin was 1.3:0.8:21.6). The initial concentration of SHL was $20 \mathrm{mg} / \mathrm{mL}$. The standard mix (including baicalin, chlorogenic acid, and forsythoside A) was prepared according to the composition ratio of SHL. Three chemical standards were weighed accurately and dissolved in Dulbecco's Modified Eagle's Medium (DMEM, Gibco).

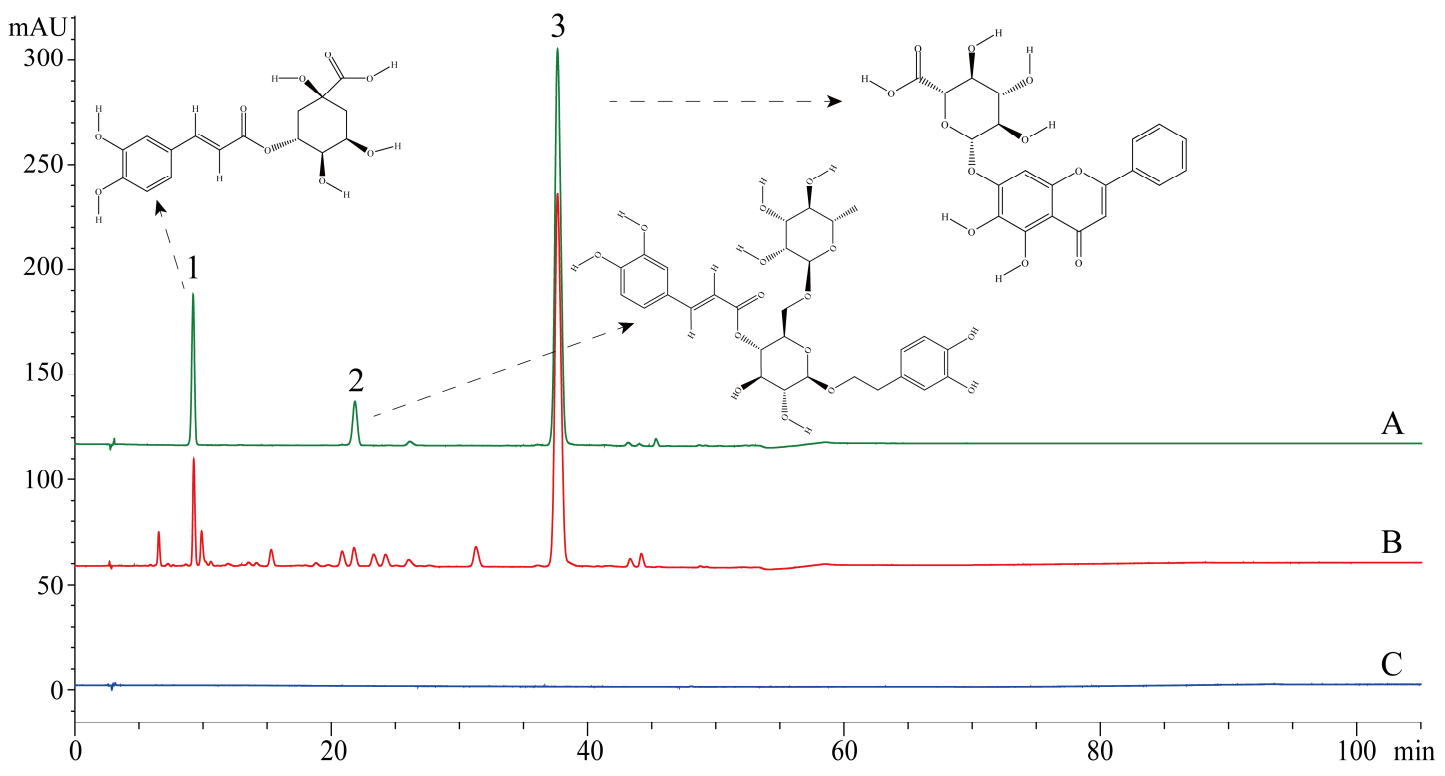

Figure 1. HPLC chromatograms of three effective constituents in SHL at $327 \mathrm{~nm}$. 1. chlorogenic acid; 2. forsythoside A; 3. Baicalin.

\subsection{Cells and Virus}

HEp-2 cells (ATCC, Manassas, VA, USA) and A549 cells (ATCC, Manassas, VA, USA) were inoculated with HAdV3 $\left(\mathrm{HAdV}_{3}\right.$, the Chinese Academy of Sciences Wuhan Institute of Virology, Wuhan, China). Cells were propagated at $37^{\circ} \mathrm{C}$ under $5 \% \mathrm{CO}_{2}$ in DMEM (Gibco, Carlsbad, CA, USA) cultured with 10\% fetal bovine serum (FBS, Gibco) and 1\% antibiotics (Gibco). Two percent FBS, instead of $10 \%$, was used to propagate virus-infected cell monolayers. The virus was stored at $-80{ }^{\circ} \mathrm{C}$, and its titer was determined by $50 \%$ tissue culture infection dose $\left(\mathrm{TCID}_{50}\right)$.

\subsection{Cytotoxicity Assay}

To determine whether SHL and CBF were toxic to HEp-2 and A549 cells, a cytotoxicity assay was measured using the cell counting kit-8 (CCK-8) assay [22]. Their $50 \%$ cytotoxic concentrations $\left(\mathrm{CC}_{50}\right)$ were determined by plotting the percentage of cell growth inhibition against the concentration of the compound drug. 


\subsection{Antiviral Effect Assay}

The antiviral activity of SHL and CBF was examined by plaque reduction assay, as previously described [23]. Briefly, $2 \times 10^{4}$ cells/well were plated in 24 -well culture plates at $37^{\circ} \mathrm{C}$ under $5 \%$ $\mathrm{CO}_{2}$ for $24 \mathrm{~h}$ and inoculated with a mixture of $100 \mathrm{TCID}_{50} /$ well virus and various concentrations of SHL and CBF in triplicate at room temperature for $2 \mathrm{~h}$. After supplementation with overlay medium (DMEM plus $2 \%$ FBS in $1 \%$ methylcellulose), they were cultured at $37{ }^{\circ} \mathrm{C}$ under $5 \% \mathrm{CO}_{2}$ for 3 days. The monolayer was then fixed with 10\% formalin and stained with $1 \%$ crystal violet, and then the plaques were counted. The minimal concentration of drugs required to inhibit $50 \%$ of the cytopathic effect $\left(50 \%\right.$ inhibitory concentration $\left.\left[\mathrm{IC}_{50}\right]\right)$ was calculated by the regression analysis of the dose-response curve generated from the data.

\subsection{Time of Addition Assay}

The antiviral activity of SHL and CBF was examined at different time points prior to and after viral inoculation by the plaque reduction assay [23]. Cells were seeded and incubated for $24 \mathrm{~h}$ as previously described. Various concentrations of SHL and the mixture were supplemented at $2 \mathrm{~h}(-2 \mathrm{~h})$ or $1 \mathrm{~h}(-1 \mathrm{~h})$ prior to viral inoculation, or $1 \mathrm{~h}(+1 \mathrm{~h})$ or $2 \mathrm{~h}(+2 \mathrm{~h})$ after viral inoculation. Supernatants were removed prior to the supplementation of overlay medium. Cells were incubated for an additional $72 \mathrm{~h}$ and examined by plaque assay.

\subsection{Attachment Assay}

Plaque reduction assay was performed to evaluate the effect of SHL and CBF on viral attachment [23]. Briefly, cells were seeded and incubated for $24 \mathrm{~h}$. Cells were pre-chilled at $4{ }^{\circ} \mathrm{C}$ for $1 \mathrm{~h}$, and the medium was replaced by a mixture of $100 \mathrm{TCID}_{50} /$ well virus and various concentrations of SHL and the CBF mixture. After incubation at $4{ }^{\circ} \mathrm{C}$ for another $3 \mathrm{~h}$, the free virus was removed. The cell monolayer was washed with ice-cold phosphate-buffered saline (PBS) three times, covered with overlay medium, incubated at $37^{\circ} \mathrm{C}$ under $5 \% \mathrm{CO}_{2}$ for an additional $72 \mathrm{~h}$, and examined by plaque assay.

\subsection{Internalization Assay}

The effect of SHL and CBF on viral internalization was also evaluated [23]. Briefly, cells were seeded and incubated for $24 \mathrm{~h}$ and pre-chilled at $4{ }^{\circ} \mathrm{C}$ for $1 \mathrm{~h}$. Cells were infected with $100 \mathrm{TCID}_{50} /$ well virus and incubated at $4{ }^{\circ} \mathrm{C}$ for another $3 \mathrm{~h}$. The virus-containing medium was replaced by fresh medium containing various concentrations of $\mathrm{SHL}$ and $\mathrm{CBF}$ in triplicate. They were shifted to culture at $37^{\circ} \mathrm{C}$. At $20 \mathrm{~min}, 40 \mathrm{~min}$, and $60 \mathrm{~min}$ intervals following the $37^{\circ} \mathrm{C}$ shift, un-internalized virus was inactivated by supplementation with acidic PBS ( $\mathrm{pH} 3$ ) for $1 \mathrm{~min}$, followed by alkaline PBS (pH 11) for neutralization. Then, PBS was replaced by fresh overlay medium. After incubation at $37^{\circ} \mathrm{C}$ for an additional $72 \mathrm{~h}$, the cell monolayer was examined by plaque assay.

\subsection{Polymerase Chain Reaction (PCR) and Quantitative PCR ( $q P C R$ )}

The antiviral activity of SHL and CBF against viral replication was further examined by PCR semi-quantitatively and by qPCR quantitatively. Briefly, $4 \times 10^{5}$ cells/well were plated into 6-well culture plates for $24 \mathrm{~h}$. A mixture of $100 \mathrm{TCID}_{50} /$ well virus and various concentrations of SHL and CBF were supplemented. They were cultured for a further $48 \mathrm{~h}$. Viral DNA was extracted with the virus DNA extraction kit for virus-infected A549 cells, HEp-2 cells, and culture supernatant, according to the manufacturer's instruction. They were then placed on ice or at $4{ }^{\circ} \mathrm{C}$ for PCR and qPCR.

The PCR and qPCR sample systems and conditions were determined according to the instruction of Premix TaqTM (TaKaRa TaqTM Version 2.0) and SYBR Premix Ex Taq II (Tli RNaseH Plus), respectively. Amplification products were analyzed semi-quantitatively by $2 \%$ agarose gel electrophoresis, and the qPCR was detected by the Step One Real-Time PCR System (Mx3005P, 
Stratagene, La, Jolla, CA, USA). The forward primer of Adv3 was 5'-ATCGATGATGCCCCAATGG-3', and the reverse primer was 5'-GGACTCAGGTACTCCGAAGCA-3'. Taking the CT value (cycle threshold) for the vertical axis and the copy number of the logarithm of concentration as abscissa, the standard curve was automatically generated by the qPCR instrument control software. The amount of virus of the experimental groups was calculated from the differences between the CT of the viral control and those of the experimental groups.

\subsection{Enzyme-Linked Immunosorbent Assay (ELISA)}

After the antiviral effect assays were performed, the culture medium was collected and assayed using the TNF-a, IFN- $\gamma$, IL-1B, and IL-6 ELISA kit according to the manufacturer's instructions. The A450 nm was determined by the ELISA reader (Thermo Scientific, Boston, MA, USA).

\subsection{Statistical Analysis}

Results are expressed as mean \pm standard deviation (S.D.). Percentage of control (infection rate; $\%$ ) was calculated from the plaque counts of the experimental groups divided by that of the viral control. Data were analyzed with analysis of variance (ANOVA) by SPSS ver. 19.0 (Armonk, NY, USA). Tukey honestly significant difference (HSD) test was used for post-hoc ANOVA comparisons. $p<0.05$ was considered statistically significant.

\section{Results}

\subsection{Cytotoxicity of SHL and CBF in A549 and HEp-2 Cells}

To determine whether SHL and CBF were toxic to cells, a cytotoxicity assay was performed using the CCK-8 assay. The estimated CC 50 of SHL and CBF were 297.7 and $148.2 \mu \mathrm{g} / \mathrm{mL}$ on A549 cells and 211.7 and $94.1 \mu \mathrm{g} / \mathrm{mL}$ on HEp-2 cells, respectively (Figure 2). Neither SHL treatment nor CBF treatment were significantly cytotoxic from concentrations of $37.1 \mu \mathrm{g} / \mathrm{mL}$ in the two cell types. Therefore, SHL and $\mathrm{CBF}$ at the concentrations of $37.1-1.2 \mu \mathrm{g} / \mathrm{mL}$ were selected in the subsequent experiments.
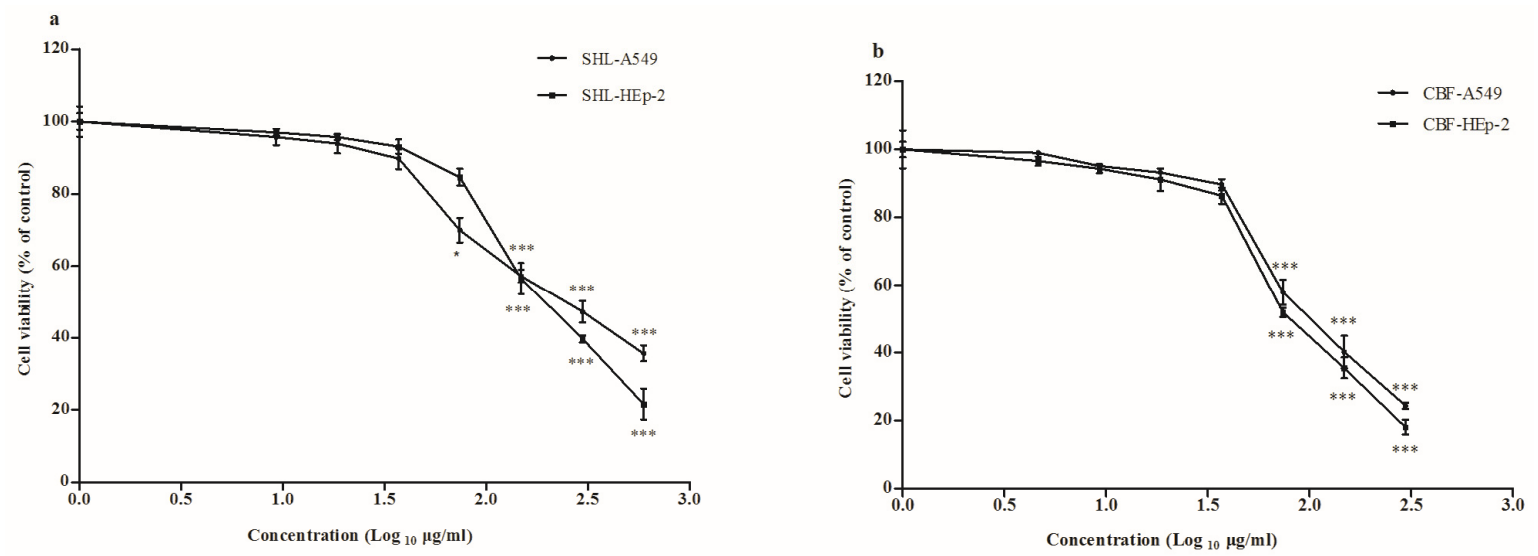

Figure 2. Shuang-Huang-Lian injectable powder (SHL) showed its cytotoxicity against host cells above the concentrations of $74.2 \mu \mathrm{g} / \mathrm{mL}$ on the A549 cells and above the concentrations of $148.3 \mu \mathrm{g} / \mathrm{mL}$ on the HEp-2 cells $(p<0.05)(\mathbf{a})$; chlorogenic acid, baicalin, and forsythia glycosides A (CBF) showed cytotoxicity above the concentrations of $74.2 \mu \mathrm{g} / \mathrm{mL}$ on both cells $(p<0.001)(\mathbf{b})$. Data are represented as mean \pm S.D. of nine tests. ${ }^{*} p<0.05 ;{ }^{* *} p<0.01 ;{ }^{* * *} p<0.001$ were compared to the cell control. 


\subsection{SHL Attenuated Virus Proliferation More Significantly Than CBF}

SHL and CBF dose-dependently decreased virus proliferation in HEp-2 and A549 cells. The effect of SHL, however, showed better suppression than CBF in both HEp-2 cells and A549 cells $(p<0.05)$ (Figure 3). This effect was significantly different at all concentrations except for 2.3 and $1.2 \mu \mathrm{g} / \mathrm{mL}$ on Hep-2 cells $(p<0.05)$. It indicated that SHL was more effective at inhibiting the proliferation of the virus than that by $\mathrm{CBF}$.
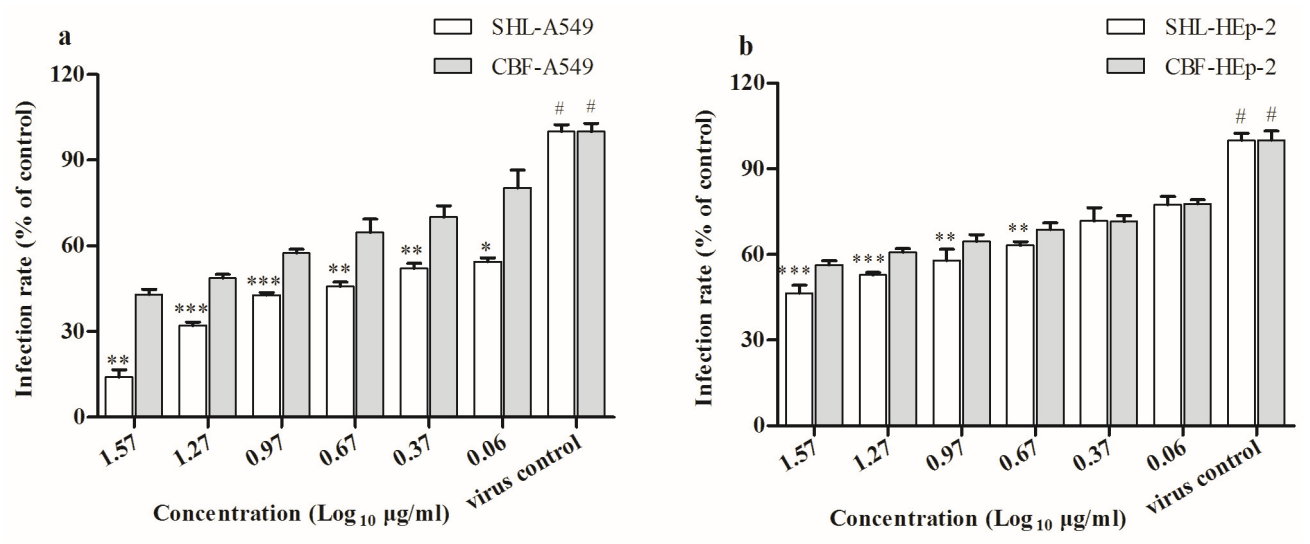

Figure 3. SHL and CBF were dose-dependently effective against human adenovirus III ( $\mathrm{HAdV}_{3}$ in both cell types as determined by plaque reduction assay $(p<0.05)$; SHL decreased more plaque formation than CBF at all the concentrations $(p<0.05)$ in A549 cells (a) and at the higher concentrations than $4.6 \mu \mathrm{g} / \mathrm{mL}(p<0.01)$ in HEp-2 cells $(\mathbf{b})$. Data are represented as mean \pm S.D. of nine tests. ${ }^{*} p<0.05$; ${ }^{* *} p<0.01 ;{ }^{* * *} p<0.001$ were compared to CBF. \# $p<0.05$ was compared to the virus control.

\subsection{SHL Decreased Plaque Formation More Than CBF When Viral Inoculation Was Given in Different Working Points}

To better understand the therapeutic intervention during virus invasion, time of addition assay in A549 and HEp-2 cells was employed to explore its working points. SHL and CBF time-dependently and dose-dependently decreased plaque formation in A549 and HEp-2 cells. SHL decreased plaque formation more than CBF when viral inoculation was given in different working points $(p<0.05)$ (Figure 4). It showed that both SHL and CBF were better at inhibiting virus activity when given before viral inoculation than after in the two cells types. As the exposure duration of cells to SHL and CBF before viral inoculation increased, so did the significance of the antiviral activity.
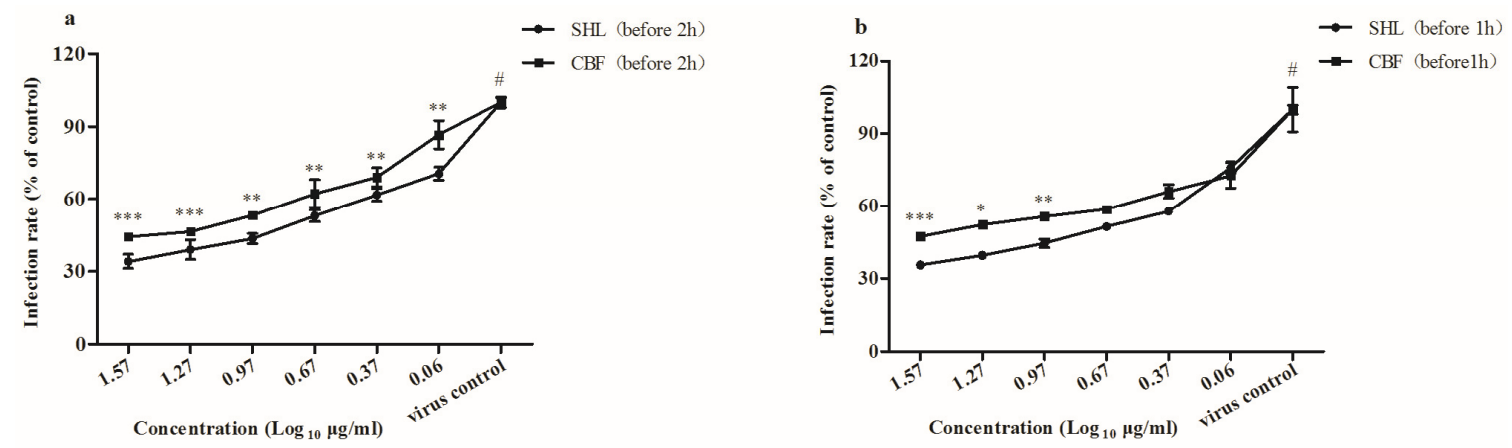

Figure 4. Cont. 

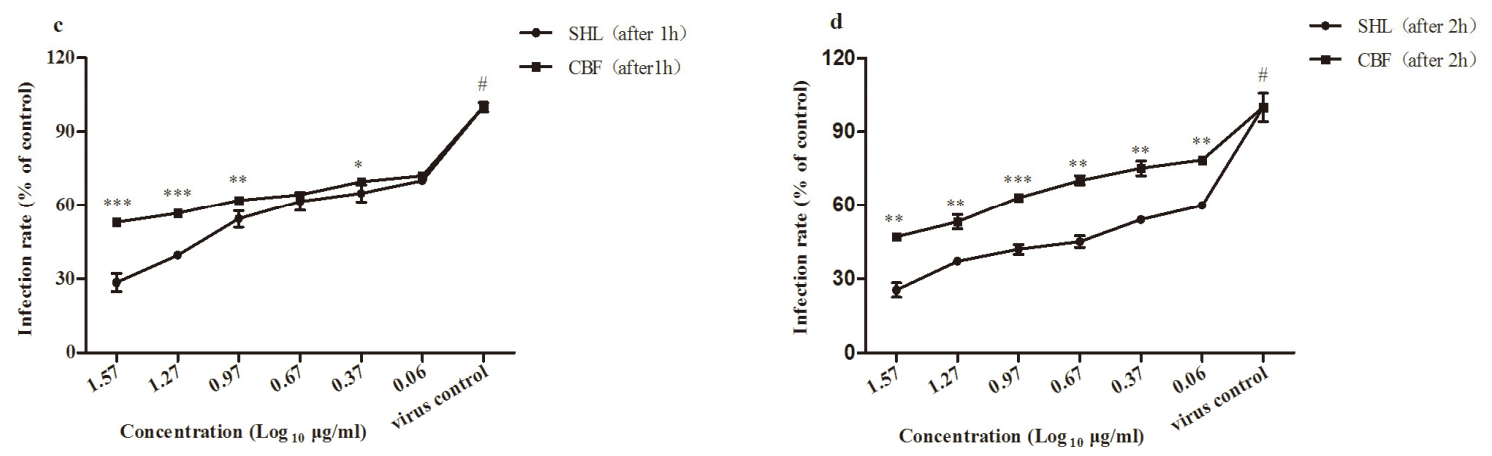

Figure 4. SHL and CBF were time-dependently and dose-dependently effective against $\mathrm{HAdV}_{3}$ when given viral inoculation in different administrations $(p<0.05)$, and SHL decreased more plaque formation than CBF in both cell types $(p<0.05)$. Data are represented as mean \pm S.D. of nine tests. ${ }^{*} p<0.05 ;{ }^{* *} p<0.01 ;{ }^{* * *} p<0.001$ were compared to CBF. \# $p<0.05$ was compared to the virus control.

\subsection{SHL Inhibited Viral Attachment Better Than CBF in A549 and HEp-2 Cells}

Because SHL and CBF anti-virus activity was mainly effective by supplementation before viral inoculation, we predicted that they worked by disrupting viral attachment and that the anti-viral effect of SHL was superior to that of CBF. Results from the attachment assay confirmed this hypothesis, as both SHL and CBF dose-dependently inhibited viral attachment. SHL decreased plaque formation more than CBF at concentrations higher than $4.6 \mu \mathrm{g} / \mathrm{mL}$ in A549 cells $(p<0.01)$ (Figure 5a), and SHL decreased plaque formation more than CBF at all concentrations in HEp-2 cells $(p<0.01)$ (Figure 5b). These results were consistent with those of the anti-viral effect assay (Figure 3) and the time course assay (Figure 4). It demonstrated that viral attachment was inhibited more with SHL than with CBF, and the effect was not significantly different between A549 and HEp-2 cells.
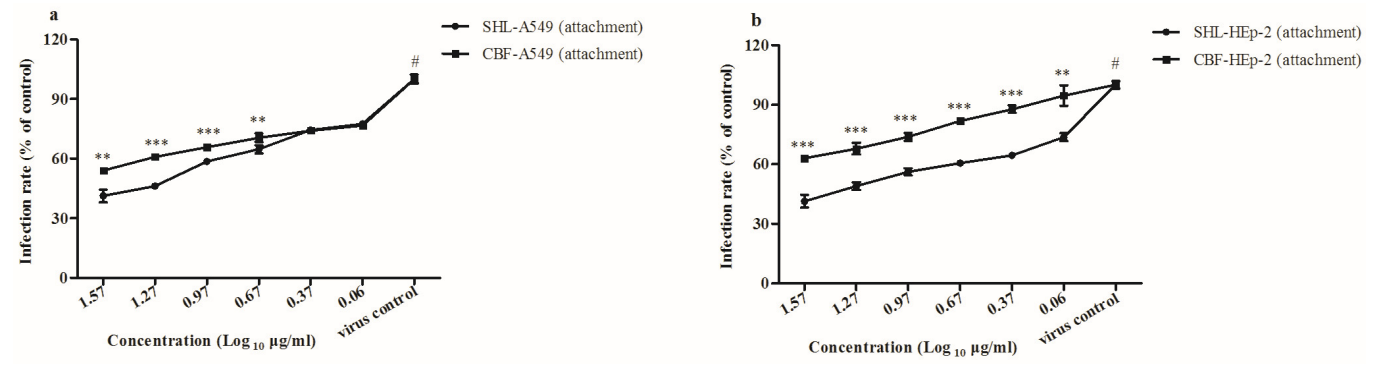

Figure 5. SHL and CBF were dose-dependently effective against viral attachment in both cell types $(p<0.05)$. SHL decreased more plaque formation than CBF at the higher concentration than $4.6 \mu \mathrm{g} / \mathrm{mL}$ in A549 cells $(p<0.05)(\mathbf{a})$, and at all the concentrations in HEp-2 cells $(p<0.05)(\mathbf{b})$. Data are represented as mean \pm S.D. of nine tests. ${ }^{*} p<0.05$; ${ }^{* *} p<0.01$; ${ }^{* * *} p<0.001$ were compared to CBF. $\# p<0.05$ was compared to the virus control.

\subsection{SHL Affected Viral Internalization More Than CBF}

The results of the internalization assay (Figure 6) were consistent with those of the above assays (Figure 4). SHL decreased plaque formation more than CBF at all concentrations except for $1.2 \mu \mathrm{g} / \mathrm{mL}$ in A549 cells (20 min) $(p<0.05)$ (Figure 6a); at all the concentrations in A549 cells (40 min) $(p<0.05)$ (Figure 6b); and at concentrations higher than $4.6 \mu \mathrm{g} / \mathrm{mL}$ in A549 cells $(60 \mathrm{~min})(p<0.01)$ (Figure 6c). In addition, SHL decreased plaque formation more than CBF at concentrations higher than $2.3 \mu \mathrm{g} / \mathrm{mL}$ in HEp-2 cells $(20 \mathrm{~min})(p<0.05)$ (Figure 6d); at concentrations higher than $2.3 \mu \mathrm{g} / \mathrm{mL}$ in HEp-2 cells (40 $\mathrm{min})(p<0.05)$ (Figure 6e); and at all concentrations in HEp-2 cells $(60 \mathrm{~min})(p<0.05)$ (Figure 6f). It indicated that the antiviral effects enhanced with increase in time. 

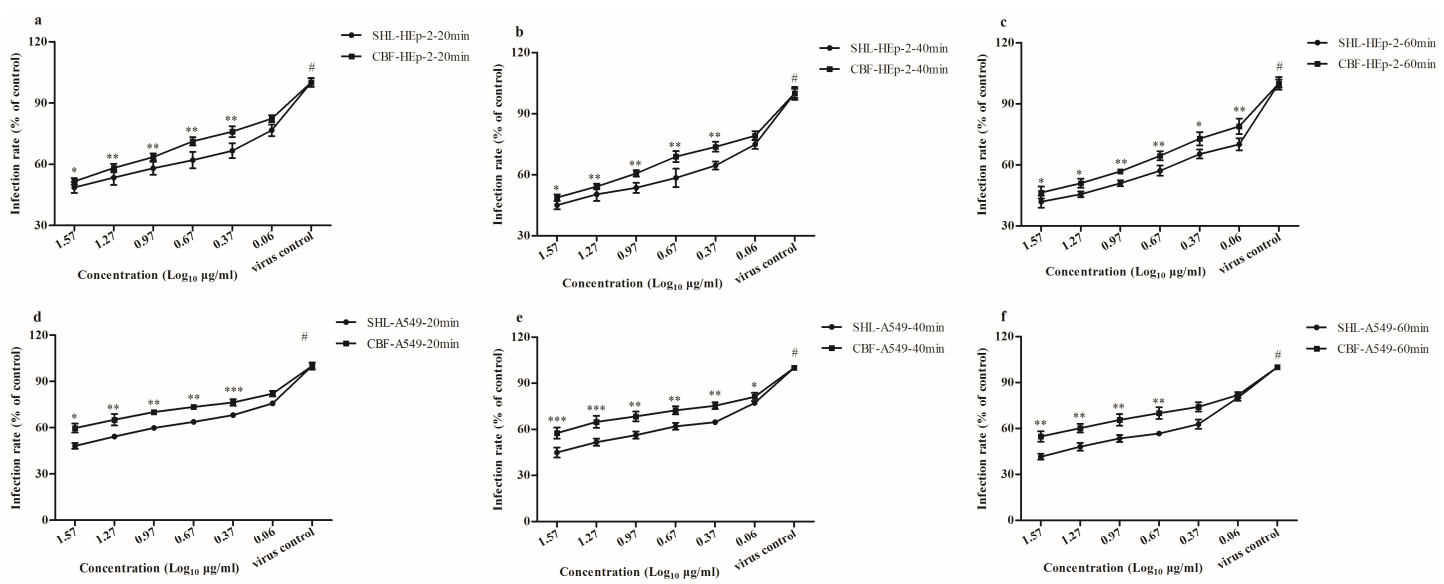

Figure 6. SHL and CBF were time-dependently and dose-dependently effective against viral internalization in both cell types $(p<0.05)$. SHL decreased more plaque formation than CBF at the high concentration $(p<0.05)$. Data are represented as mean \pm S.D. of nine tests. ${ }^{*} p<0.05$; ** $p<0.01 ;{ }^{* * *} p<0.001$.

\subsection{SHL Significantly Suppressed Viral DNA Replication in A549 and HEp-2 Cells Compared to CBF}

Data from the semi-quantification of viral DNA by agarose gel electrophoresis were comparable to those of qPCR (Figure 7). The results of the semi-quantification and quantification of viral DNA had different trends in cells and in the suspension. SHL markedly decreased viral amounts compared to CBF at all concentrations $(p<0.001)$ in A549 cells and at concentrations higher than $4.6 \mu \mathrm{g} / \mathrm{mL}$ $(p<0.01)$ in the suspension. In addition, SHL markedly decreased the amount of virus compared to $\mathrm{CBF}$ at concentrations higher than $4.6 \mu \mathrm{g} / \mathrm{mL}(p<0.05)$ in HEp-2 cells. The difference, however, was not significant in the suspension.
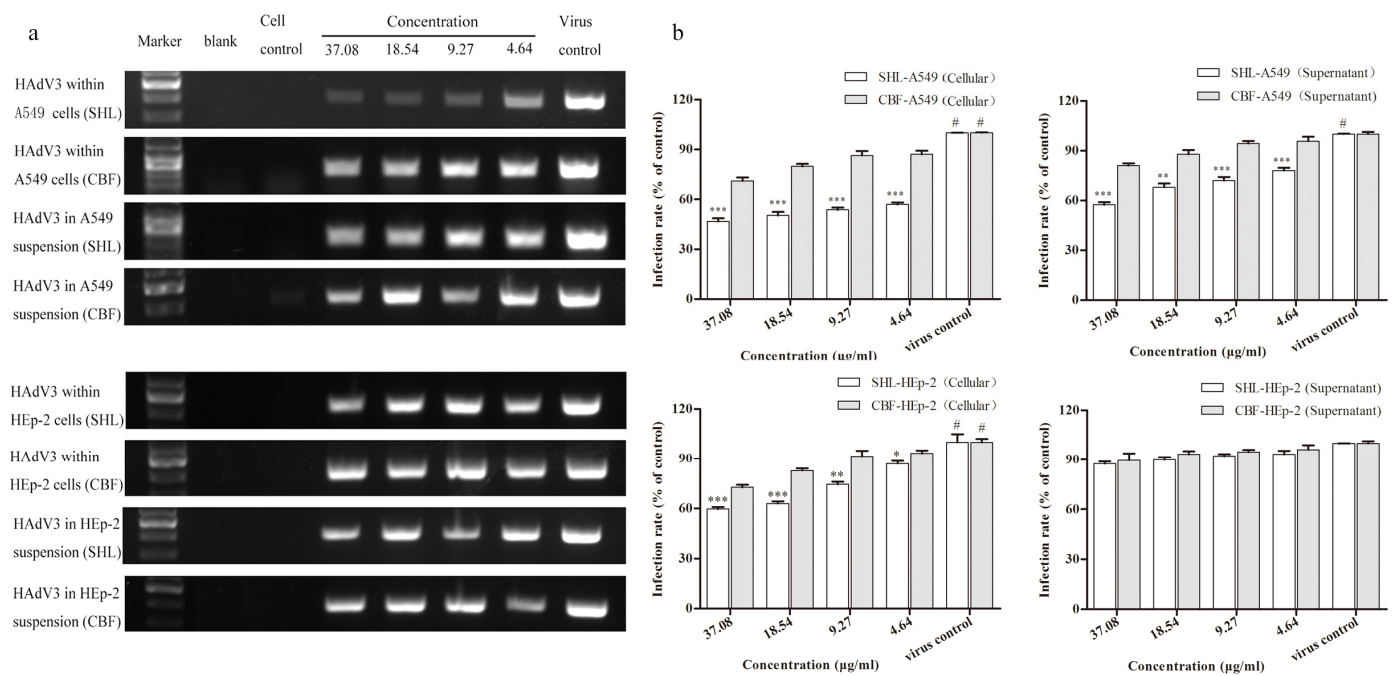

Figure 7. The PCR result of the quantification of viral DNA by the agarose gel electrophoresis (a) was comparable to that of the qPCR (b). SHL markedly decreased the viral amounts more than CBF at all concentrations $(p<0.001)$ within A549 cells $(p<0.001)$ and in the suspension $(p<0.05)$; and at all the concentrations within HEp-2 cells $(p<0.05)$; and there was no significant difference in the suspension $(p>0.05)$. Data are represented as mean \pm S.D. of three tests. ${ }^{*} p<0.05 ;{ }^{* *} p<0.01$; ${ }^{* * *} p<0.001$ were compared to CBF. \# $p<0.05$ was compared to the virus control. 


\subsection{SHL Attenuated Inflammatory Effects Significantly More Than CBF in HAdV ${ }_{3}$-Stimulated A549 and HEp-2 Cells}

Because virus infection can lead to the production of the pro-inflammatory cytokines IFN- $\gamma$, TNF- $\alpha$, IL-1ß, and IL- 6 , which contribute to inflammation, the expressions of these cytokines were measured. Results showed that SHL and CBF significantly suppressed the secretion of these cytokines in both cell types compared to the virus control group (Figure 8). SHL, however, was more effective than CBF at decreasing the secretion of TNF- $\alpha$ at the concentrations of 37.1 and $18.5 \mu \mathrm{g} / \mathrm{mL}$ in both A549 and HEp-2 cells (Figure 8a,b). In addition, SHL suppressed the secretion of IL-1ß significantly more than CBF at the concentrations of $37.1,18.5$, and $9.3 \mu \mathrm{g} / \mathrm{mL}$ in A549 cells and at the concentration of $37.1 \mu \mathrm{g} / \mathrm{mL}$ in HEp-2 cells (Figure 8c,d). At the concentration of $37.1 \mu \mathrm{g} / \mathrm{mL}$, the secretion of IL-6 in HEp-2 cells and the secretion of IFN- $\gamma$ in A549 cells in the SHL group was less than those in the CBF group (Figure 8f,g). There was no significant difference between the treatment groups for IL-6 secretion in A549 cells and IFN- $\gamma$ secretion in HEp-2 cells (Figure 8e,h). Taken together, these results suggest that SHL can attenuate the inflammatory effects in $\mathrm{HAdV}_{3}$-stimulated A549 and HEp-2 cells more than $\mathrm{CBF}$.
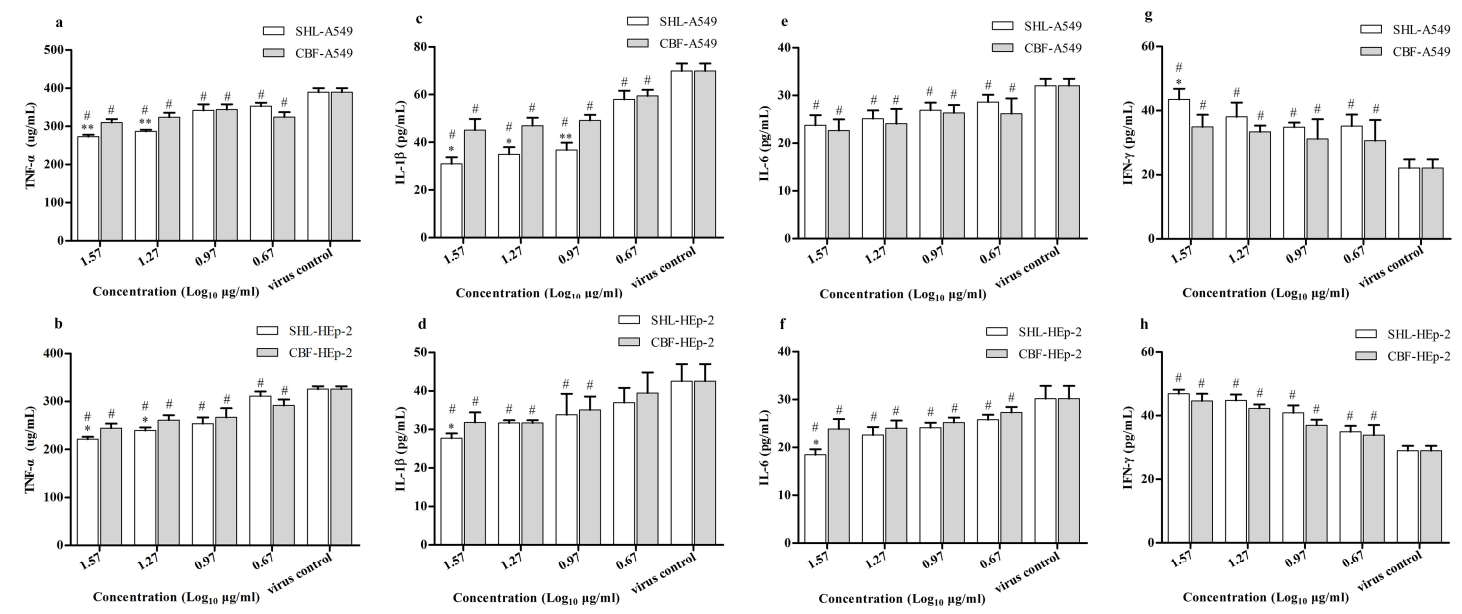

Figure 8. The expressions of TNF- $\alpha$, IL-1ß, and IL- 6 were lower and the expression of IFN- $\gamma$ was higher in both cell types treated with SHL than with CBF. Data are represented as mean \pm S.D. of three tests. ${ }^{*} p<0.05$; ${ }^{* *} p<0.01$; ${ }^{* * *} p<0.001$ were compared to CBF. \# $p<0.05$ was compared to the virus control.

\section{Discussion}

Herb formula or natural compound drugs have been shown to be effective in the TCM clinic. Indeed, various compounds contained in herbs or formula (mixture of herbs) are used therapeutically and play an important role in rebalancing disorders in organisms. TCM formulas are always considered multi-component and multi-target agents, which is essentially the same strategy as that during combination therapy with multi-component drugs. The ratios of bioactive ingredients affect efficacy and toxicity, as occurs with highly active antiretroviral therapy and ginaton. Therefore, this study was performed to determine a consistent dose and compounding ratio of CBF. According to the results of HPLC (Figure 1), chlorogenic acid (1.3\%), forsythoside A $(0.8 \%)$, and baicalein $(21.6 \%)$ were the major components of SHL. CBF was a combination of the ratio of the results of HPLC.

We used a plaque reduction assay to determine the effects of SHL and CBF in both HEp-2 and A549 cells. Variation of the anti-virus activities of SHL and BCF was correlated with its working point after administration. According to our study, the antiviral ability of SHL was greater than that of $\mathrm{CBF}$ when the cells were treated before viral inoculation. This antiviral potency of SHL was further confirmed by its ability to inhibit viral attachment and internalization (Figures 5 and 6), suggesting that the anti-viral ability of SHL is mainly a preventative effect. Therefore, longer pre-incubation times improve the anti-viral effects of the two drugs. Moreover, different anti-virus assays and different 
respiratory tract cell lines were tested. Compared with $\mathrm{CBF}$, SHL had a high $\mathrm{CC}_{50}$ and inhibited virus entry and replication. Therefore, SHL is safer, more effective, and more readily available than CBF for the prevention and management of virus-induced airway injuries.

Although both SHL and CBF can disrupt virus DNA amplification and destroy virus particles, SHL treatment reduced virus DNA load in cells more than CBF. The reduction in virus DNA load was greater with SHL than CBF within or out of the two cell types, A549 and HEp-2 cells. In cell suspensions, the anti-viral effects of intervention with SHL were greater than the effects with CBF in A549 cells but not HEp-2 cells, suggesting that SHL was a more effective drug at improving the lower respiratory tract infections in virus. What is more, the sensitivity of the virus to the two cells was different; the amount of the virus released was also different; and the low levels of virus in the supernatant of the cells may be one reason for the absence of differences between the two cells.

Virus-induced secretion of cytokines, such as INF, TNF, and IL, contribute to innate immunity against viral infection. Therefore, variations in the levels of IFN- $\gamma$, TNF- $\alpha$, IL-1B, and IL- 6 were compared between SHL and CBF treatment groups [23-27]. According to our study, both SHL and CBF attenuated the production of pro-inflammatory cytokines IL-1B, IL-6, and TNF- $\alpha$ and promoted the release of INF- $\gamma$ in vitro as compared to the virus control group, suggesting that SHL and CBF can suppress inflammation stimulated by virus. In addition, the regulation of inflammation markers was greater for SHL than that for CBF in both cell types. Consistent with this finding, SHL had a multi-channel anti-virus effect and protected against respiratory injury from $\mathrm{HAdV}_{3}$ infection better than the monomer combination.

SHL has been used as an empirical therapy to treat virus infection in the TCM clinic for many years. This study is the first to evaluate comprehensively the role of SHL as an antiviral agent against $\mathrm{HAdV}_{3}$. Furthermore, the antiviral activity of SHL was compared to CBF-the main compound combination in SHL-to evaluate the potential anti-virus activity of the effective parts and its composition. Parallel doses and combination ratios of these ingredients were determined and controlled by HPLC. We demonstrated that both SHL and CBF effectively inhibited $\mathrm{HAdV}_{3}$-induced injuries by preventing viral penetration; un-coating; mRNA translation; protein synthesis; genome replication; and virus assembly and release to counteract viral infection. SHL appeared to be very promising in terms of efficacy and toxicity. This study also provides a primary explanation for the hypothesis that multiple bioactive ingredients with multiple targets of TCM are involved in the antivirus mechanism of SHL. Although CBF was not an ideal combination of the compound ingredient, our findings are helpful for related drug discovery and merit further exploration.

Acknowledgments: This work was supported by Grinds Gathers Project of Guangdong Province, China (2010A090200076).

Author Contributions: J.-B.L. and X.X. designed the study. Q.M., D.L. and S.S. wrote the paper. Q.M., Q.Y. and C.S. collected the samples. Q.M., X.X., D.L., S.S., Q.Y. and C.S. performed tests and analyzed the data. Q.M. thoroughly revised the manuscript.

Conflicts of Interest: The authors declare no conflict of interest.

\section{Abbreviations}

The following abbreviations are used in this manuscript:

$\begin{array}{ll}\text { ANOVA } & \begin{array}{l}\text { analysis of variance } \\ \text { chlorogenic acid, baicalin, forsythia glycosides A }\end{array} \\ \text { CBF } & 50 \% \text { cytotoxic concentrations } \\ \text { CC50 } & \text { cell counting kit-8 } \\ \text { CCK-8 } & \text { diode array detector } \\ \text { DAD } & \text { Dulbecco's Modified Eagle's Medium } \\ \text { DMEM } & \text { enzyme-linked immunosorbent assay }\end{array}$




$\begin{array}{ll}\text { FBS } & \text { fetal bovine serum } \\ \text { HAdV } & \text { human adenovirus } \\ \text { HIV } & \text { human immunodeficiency virus } \\ \text { HPLC } & \text { high performance liquid chromatography } \\ \text { HSD } & \text { honestly significant difference } \\ \text { IC50 } & 50 \% \text { inhibitory concentration } \\ \text { IFN } & \text { interferon } \\ \text { IL } & \text { interleukin } \\ \text { PCR } & \text { polymerase chain reaction } \\ \text { qPCR } & \text { quantitative polymerase chain reaction } \\ \text { S.D. } & \text { standard deviation } \\ \text { SHL } & \text { Shuang-Huang-Lian injectable powder } \\ \text { TCID50 } & \text { 50\% tissue culture infection dose } \\ \text { TCM } & \text { traditional Chinese medicine } \\ \text { TNF- } \alpha & \text { tumor necrosis factor alpha } \\ \text { DNA } & \text { deoxyribonucleic acid }\end{array}$

\section{References}

1. Dehghan, S.; Liu, E.B.; Seto, J.; Torres, S.F.; Hudson, N.R.; Kajon, A.E.; Metzgar, D.; Dyer, D.W.; Chodosh, J.; Jones, M.S.; et al. Five genome sequences of subspecies B1 human adenoviruses associated with acute respiratory disease. J. Virol. 2012, 86, 635-636. [CrossRef] [PubMed]

2. Robinson, C.M.; Zhou, X.; Rajaiya, J.; Yousuf, M.A.; Singh, G.; DeSerres, J.J.; Walsh, M.P.; Wong, S.; Seto, D.; Dyer, D.W.; et al. Predicting the next eye pathogen: Analysis of a novel adenovirus. MBio 2013, 4, e00595:1-e00595:12. [CrossRef] [PubMed]

3. Yun, H.C.; Fugate, W.H.; Murray, C.K.; Cropper, T.L.; Lott, L.; McDonald, J.M. Pandemic influenza virus 2009 H1N1 and adenovirus in a high risk population of young adults: Epidemiology, comparison of clinical presentations, and coinfection. PLoS ONE 2014, 9, e85094. [CrossRef] [PubMed]

4. Lu, Q.B.; Tong, Y.G.; Wo, Y.; Wang, H.Y.; Liu, E.M.; Gray, G.C.; Liu, W.; Cao, W.C. Epidemiology of human adenovirus and molecular characterization of human adenovirus 55 in China, 2009-2012. Influenza Other Respir. Viruses 2014, 8, 302-308. [CrossRef] [PubMed]

5. Barrero, P.R.; Valinotto, L.E.; Tittarelli, E.; Mistchenko, A.S. Molecular typing of adenoviruses in pediatric respiratory infections in Buenos Aires, Argentina (1999-2010). J. Clin. Virol. 2012, 53, 145-150. [CrossRef] [PubMed]

6. Alkhalaf, M.A.; Guiver, M.; Cooper, R.J. Genome stability of adenovirus types 3 and 7 during a simultaneous outbreak in Greater Manchester, UK. J. Med. Virol. 2015, 87, 17-24. [CrossRef] [PubMed]

7. Ampuero, J.S.; Ocana, V.; Gomez, J.; Gamero, M.E.; Garcia, J.; Halsey, E.S.; Laguan-Torres, V.A. Adenovirus respiratory tract infections in Peru. PLoS ONE 2012, 7, e46898. [CrossRef] [PubMed]

8. Guo, L.; Gonzalez, R.; Zhou, H.; Wu, C.; Vernet, G.; Wang, Z.; Wang, J. Detection of three human adenovirus species in adults with acute respiratory infection in China. Eur. J. Clin. Microbiol. Infect. Dis. 2012, 31, 1051-1058. [CrossRef] [PubMed]

9. Lai, C.Y.L.C. Adenovirus serotype 3 and 7 infection with acute respiratory failure in children inTaiwan, 2010-2011. PLOS ONE 2013, 8, e53614.

10. Lee, W.J.; Jung, H.D.; Cheong, H.M.; Kim, K. Molecular epidemiology of a post-influenza pandemic outbreak of acute respiratory infections in Korea caused by human adenovirus type 3. J. Med. Virol. 2015, 87, 10-17. [CrossRef] [PubMed]

11. Wang, H.S.; Cheng, F.; Shi, Y.Q.; Li, Z.G.; Qin, H.D.; Liu, Z.P. Hypotensive response in rats and toxicological mechanisms induced by Shuanghuanglian, an herbal extract mixture. Drug Discov. Ther. 2010, 4, 13-18. [PubMed]

12. McDougall, B.; King, P.J.; Wu, B.W.; Hostomsky, Z.; Reinecke, M.G.; Robinson, W.J. Dicaffeoylquinic and dicaffeoyltartaric acids are selective inhibitors of human immunodeficiency virus type 1 integrase. Antimicrob. Agents Chemother. 1998, 42, 140-146. [PubMed]

13. Chiang, L.C.; Chiang, W.; Chang, M.Y.; Ng, L.T.; Lin, C.C. Antiviral activity of Plantago major extracts and related compounds in vitro. Antivir. Res. 2002, 55, 53-62. [CrossRef] 
14. Liu, Z.; Zhao, J.; Li, W.; Shen, L.; Huang, S.; Tang, J.; Duan, J.; Fang, F.; Huang, Y.; Chang, H.; et al. Computational screen and experimental validation of anti-influenza effects of quercetin and chlorogenic acid from traditional Chinese medicine. Sci. Rep. 2016, 6. [CrossRef] [PubMed]

15. Gamaleldin, E.K.M.; Matei, M.F.; Jaiswal, R.; Illenberger, S.; Kuhnert, N. Neuraminidase inhibition of Dietary chlorogenic acids and derivatives-Potential antivirals from dietary sources. Food Funct. 2016, 7, 2052-2059. [CrossRef] [PubMed]

16. Li, X.; Liu, Y.; Hou, X.; Peng, H.; Zhang, L.; Jiang, Q.; Shi, M.; Ji, Y.; Wang, Y.; Shi, W. Chlorogenic acid inhibits the replication and viability of enterovirus 71 in vitro. PLOS ONE 2016, 7, 2052-2059. [CrossRef] [PubMed]

17. Zhang, C.J.; Gu, L.G.; Yu, H.T. Antagonism of baicalin on cell cyclical distribution and cell apoptosis in A549 cells infected with influenza A (H1N1) virus. Bing Du Xue Bao 2011, 27, 108-116. (In Chinese). [PubMed]

18. Moghaddam, E.; Teoh, B.T.; Sam, S.S.; Lani, R.; Hassandarvish, P.; Chik, Z.; Yueh, A.; Abubakar, S.; Zandi, K. Baicalin, a metabolite of baicalein with antiviral activity against dengue virus. Sci. Rep. 2014, 4. [CrossRef] [PubMed]

19. Cheng, K.; Wu, Z.; Gao, B.; Xu, J. Analysis of influence of baicalin joint resveratrol retention enema on the TNF-alpha, SIgA, IL-2, IFN-gamma of rats with respiratory syncytial virus infection. Cell Biochem. Biophys. 2014, 70, 1305-1309. [CrossRef] [PubMed]

20. Li, H.; Wu, J.; Zhang, Z.; Ma, Y.; Liao, F.; Zhang, Y.; Wu, G. Forsythoside A inhibits the avian infectious bronchitis virus in cell culture. Phytother. Res. 2011, 25, 338-342. [CrossRef] [PubMed]

21. Chen, L.; Zhang, Y.; Liu, J.; Wei, L.; Song, B.; Shao, L. Exposure of the murine RAW 264.7 macrophage cell line to dicalcium silicate coating: Assessment of cytotoxicity and pro-inflammatory effects. J. Mater. Sci. Mater. Med. 2016, 27. [CrossRef] [PubMed]

22. Chang, J.S.; Wang, K.C.; Shieh, D.E.; Hsu, F.F.; Chiang, L.C. Ge-Gen-Tang has anti-viral activity against human respiratory syncytial virus in human respiratory tract cell lines. J. Ethnopharmacol. 2012, 139, 305-310. [CrossRef] [PubMed]

23. Bartee, E.; Mohamed, M.R.; McFadden, G. Tumor necrosis factor and interferon: Cytokines in harmony. Curr. Opin. Microbiol. 2008, 11, 378-383. [CrossRef] [PubMed]

24. McFadden, G.; Mohamed, M.R.; Rahman, M.M.; Bartee, E. Cytokine determinants of viral tropism. Nat. Rev. Immunol. 2009, 9, 645-655. [CrossRef] [PubMed]

25. Fang, J.; Cheng, Q. Etiological mechanisms of post-stroke depression: A review. Neurol. Res. 2009, 31, 904-909. [CrossRef] [PubMed]

26. Trefler, J.; Paradowska-Gorycka, A.; Lacki, J.K. Influence of genetic factors on development and severity of rheumatoid arthritis-Part II. Pol. Merkur. Lekarski 2009, 27, 161-165. [PubMed]

27. Masters, S.L.; Simon, A.; Aksentijevich, I.; Kastner, D.L. Horror autoinflammaticus: The molecular pathophysiology of autoinflammatory disease. Annu. Rev. Immunol. 2009, 27, 621-668. [CrossRef] [PubMed] 